\title{
Inner-ring Deiodination of 3,5,3'-Triiodothyronine in the In Situ Perfused Guinea Pig Placenta
}

Maria I. Castro, Lewis E. Braverman, Sharon Alex, Chih-Fang Wu, and Charles H. Emerson

Division of Endocrinology and Metabolism, Department of Medicine, University

of Massachusetts Medical School, Worcester, Massachusetts 01605

\section{Abstract}

Broken cell preparations of rat and human placentas contain an inner (tyrosyl)-ring iodothyronine deiodinase enzyme with greatest activity when the substrate is $3,5,3^{\prime}$-triiodothyronine $\left(T_{3}\right)$. This report describes the deiodination of $T_{3}$ in the intact placenta and the effect of sodium iopanoate (IA) and propylthiouracil (PTU) on $T_{3}$ deiodination. Under nembutal anesthesia, the placenta of 60-65-d-old pregnant guinea pigs was surgically exposed, a single umbilical artery and the umbilical vein were cannulated, and the fetus was removed. In a temperature-controlled chamber $\left(37^{\circ} \mathrm{C}\right)$, the fetal side of the placenta was perfused through the umbilical artery at a rate of $1 \mathrm{ml} / \mathrm{min}$ with $3 \%$ bovine serum albumin Krebs-Henseleit buffer containing $0.14 \mathrm{nM}$ outer ring labeled [ $\left.{ }^{125} I\right] T_{3}$. Placenta effluent fractions were collected at timed intervals from the umbilical vein canulla throughout a 120-min perfusion period. The contents of the perfusion buffer and the various effluent fractions were analyzed for their iodothyronine content by high pressure liquid chromatography. In five experiments, the percent composition of ${ }^{125}$ I-labeled iodothyronines in the perfusion buffer and placenta effluent was $95.3 \pm 1.0$ (mean \pm SE) and $70.2 \pm 2.1$ for $T_{3}(P<0.01), 2.5 \pm 0.7$ and 20.1 \pm 1.8 for $3,3^{\prime}-T_{2}(P<0.01)$, and 0 and $8.2 \pm 0.9$ for $3^{\prime}-T_{1}$. There was no difference between the percent [ $\left.{ }^{125} I\right]$ iodide in the perfusion buffer and in the placenta effluents. When placentas were perfused with $I A$ and $\left[{ }^{125} I\right] T_{3}$, after perfusion with $\left[{ }^{125} \mathrm{I}\right] \mathrm{T}_{3}$ alone, there was a significant increase $(P<0.01)$ in the percent $\left[^{125} \mathrm{I}\right] \mathrm{T}_{3}$ in the placenta effluents, and a significant decrease in $\left[{ }^{125} I\right] 3,3^{\prime}-T_{2}(P<0.01)$ and $\left[{ }^{125} I\right] 3^{\prime}-T_{1}(P<0.01)$. In contrast, PTU did not affect the composition of labeled iodothyronines in the placenta effluents, despite the fact that the addition of PTU significantly $(P<0.001)$ inhibits the inner-ring deiodination of $\left[^{125} \mathrm{IT}_{3}\right.$ in human or guinea pig placenta microsomes in the presence of low $(0.25 \mathrm{mM})$ concentrations of dithiothreitol. The present studies demonstrate that $T_{3}$ is actively deiodinated in the inner ring to $3,3^{\prime}-T_{2}$ by the intact guinea pig placenta. A portion of $3,3^{\prime}-T_{2}$ is further deiodinated in the inner ring to generate $3^{\prime}-T_{1}$. No outer ring deiodination of $T_{3}$ was seen under the conditions employed. IA, but not PTU, inhibits $T_{3}$ deiodination in the placenta perfused in situ. We conclude that the placenta is probably a site for fetal $T_{3}$ metabolism.

Address reprint requests to Dr. Emerson, Division of Endocrinology and Metabolism, University of Massachusetts Medical School, Worcester, MA 01605.

Received for publication 26 November 1984 and in revised form 5 July 1985.

J. Clin. Invest.

(C) The American Society for Clinical Investigation, Inc.

0021-9738/85/11/1921/06 \$1.00

Volume 76, November 1985, 1921-1926

\section{Introduction}

The placenta receives a large percentage of the fetal cardiac output (1), and, as we and others have reported (2-7), contains enzymes that deiodinate thyroid hormones. These observations support the possibility that the placenta is an important site for fetal thyroid hormone metabolism. Deiodination of the iodothyronines can occur in the phenolic ( $5^{\prime}$ or outer) or in the tyrosyl ( 5 or inner) rings. These deiodinative pathways play a major role in the metabolism of thyroxine $\left(\mathrm{T}_{4}\right),{ }^{1}$ generating the metabolically active iodothyronine, 3,5,3'-triiodothyronine $\left(\mathrm{T}_{3}\right)$, and the metabolically inactive iodothyronine, 3,3',5'-triiodothyronine $\left(\mathrm{rT}_{3}\right)$. Deiodination is also the principal pathway for the metabolism of $\mathrm{T}_{3}$, which results in the formation of the inactive diiodothyronines, $3,3^{\prime}-\mathrm{T}_{2}$ and $3,5-\mathrm{T}_{2}$, as well as the inactive monoiodothyronines, $3^{\prime}-T_{1}$ and $3-T_{1}$. Thus, placental deiodination is potentially an important mechanism for the modulation of fetal thyroid hormone action. While detailed studies of deiodination have been performed in placenta homogenates and subcellular fractions $(6,8)$, there is little information on iodothyronine deiodination in the intact placenta (9).

In this study, we discovered the metabolic fate of $\mathrm{T}_{3}$ when perfused through the fetal side of the guinea pig placenta in situ. Since previous studies employing placenta homogenates have shown an inhibitory effect of propylthiouracil (PTU) and sodium iopanoate (IA) on $\mathrm{T}_{4}$ deiodination (8), the effect of these drugs on $T_{3}$ metabolism in the intact placenta was evaluated.

\section{Methods}

Pregnant guinea pigs were obtained from Davidson Mill Farms (Jamesburg, NJ) and were studied after $60 \mathrm{~d}$ of gestation. Papavarin hydrochloride was purchased from Eli Lilly Co. (Indianapolis, IN) and PE60 polyethylene tubing was obtained from Fisher Scientific Co. (Medford, MA). Nonradioactive $3^{\prime}-T_{1}, 3,3^{\prime}-T_{2}$, and $3^{\prime}, 5^{\prime}-T_{2}$ were obtained from Hennig Berlin GMBH (Berlin, Federal Republic of Germany). Nonradioactive $T_{3}, T_{4}$, reverse $T_{3}, 3,5-T_{2}$, and PTU were obtained from Sigma Chemical Co. (St. Louis, MO). ${ }^{125} \mathrm{I}_{-} \mathrm{T}_{3}$ was purchased from New England Nuclear (Boston, MA) and from Cambridge Medical Diagnostics (Billerica, MA). Its specific activity ranged from 1,133 to $2,000 \mu \mathrm{Ci} / \mu \mathrm{g}$. Iopanoic acid powder was a gift from Sterling Winthrop Research Institute (Renselear, NY) and the sodium salt (IA) was produced by dissolving iopanoic acid powder in sodium hydroxide.

Surgical procedure. One-pass placenta perfusions were performed using a technique modified from Kihlstrom and Kihlstrom (10). Pregnant guinea pigs were studied after 60 gestational days and anesthesia was

1. Abbreviations used in this paper: DTT, dithiothreitol; HPLC, high performance liquid chromotography; IA, sodium iopanoate; $\mathrm{KH}$, KrebsHenseleit buffer, PTU, propylthiouracil; $\mathrm{rT}_{3}, 3,3^{\prime}, 5^{\prime}$-triiodothyronine; $T_{1}$, monoiodothyronine; $T_{2}$, diiodothyronine; $T_{3}, 3,5,3^{\prime}$-triiodothyronine; $T_{4}$, thyroxine. 
induced with an i.p. injection of nembutal $(40 \mathrm{mg} / \mathrm{kg})$. If necessary, further injections of 5-10 mg nembutal were administered during the perfusion. After induction of anesthesia, a laparotomy was performed and a single fetus was exposed through a small uterine incision. Both uterus and placenta were left within the maternal abdominal cavity to minimize hemodynamic changes in the maternal circulation to the placenta. The fetal umbilical arteries and vein were cleared of fetal membranes. To facilitate cannulation, we caused the dilation of vessels by the topical application of $4 \%$ papavarin. The umbilical vein and one fetal artery were cannulated with PE60 polyethylyne tubing with an internal diameter of 0.03 in and external diameter of $0.048 \mathrm{in}$. The remaining vessels leading to the fetus were tied off and the fetus was removed. The fetal side of the placenta was then perfused at a rate of 1.0 $\mathrm{ml} / \mathrm{min}$ through the umbilical artery from a reservoir containing $3 \%$ bovine serum albumin (BSA) in Krebs-Henseleit (KH) buffer $(0.110 \mathrm{M}$ $\mathrm{NaCl}, 2.4 \mathrm{mM} \mathrm{CaCl}, 4.4 \mathrm{mM} \mathrm{KCl}, 1.1 \mathrm{mM} \mathrm{KH}_{2} \mathrm{PO}_{4}, 1.1 \mathrm{mM}$ $\mathrm{MgSO}_{4} \cdot 7 \mathrm{H}_{2} \mathrm{O}$, and $25.0 \mathrm{mM} \mathrm{NaHCO} 3, \mathrm{pH}$ 7.4). Placental pressure was monitored with a string-gauge transducer and catheter positions were adjusted to maintain a placental pressure between $20-40 \mathrm{mmHg}$. The uterine opening was covered with gauze that had been soaked in $0.9 \%$ saline to keep the cannulated placental vessels moist.

Experimental procedure. A 20-min preperfusion of the placenta with $\mathrm{KH}$ buffer was performed before the start of each experiment to ensure stabilization of the placenta. During the preperfusion as well as during the experimental period, the dam and the perfusion reservoir were kept in a plexiglass chamber thermostatically maintained at $37^{\circ} \mathrm{C}$. During the experimental period, $\left[{ }^{125} \mathrm{I}\right] \mathrm{T}_{3}$ was added to the perfusion reservoir to obtain a concentration of 0.104 to $0.121 \mu \mathrm{Ci} / \mathrm{ml}$. Depending on its specific activity, the total $T_{3}$ concentration in the perfusion buffer ranged from 0.08 to $0.14 \mathrm{nM}$. The percent-free $\mathrm{T}_{3}$ in the perfusion buffer was $0.4 \pm 0.01 \%$ (mean $\pm \mathrm{SE}$ ) determined by equilibrium dialysis as previously described in our laboratory (11). Thus, the free $\left[{ }^{125} \mathrm{I}\right] \mathrm{T}_{3}$ that perfused the placenta ranged from 0.32 to $0.56 \mathrm{pM}$. The placenta effluent samples were then collected at timed intervals and the iodothyronine content of the perfusion buffer and placenta effluent samples was analyzed by high pressure liquid chromatography (HPLC) (see below).

In five experiments, the placenta was perfused with $\left[{ }^{125} \mathrm{I}\right] \mathrm{T}_{3}$ alone for $120 \mathrm{~min}$. In other experiments, placentas were perfused with $\left[{ }^{125} \mathrm{I}\right] \mathrm{T}_{3}$ alone for $40 \mathrm{~min}$. At $40 \mathrm{~min}$, the perfusion buffer was changed to one that contained ${ }^{125} \mathrm{I}_{-} \mathrm{T}_{3}$ and a substance to be tested for inhibition of placenta inner ring deiodinase activity; this perfusion was continued for another $40 \mathrm{~min}$. The $\mathrm{pH}$ of the perfusion buffer did not change when any of the test substances were added to the perfusion buffer. Finally, for the remaining $40-\mathrm{min}$ period the placenta was perfused with [ $\left.{ }^{125} \mathrm{I}\right] \mathrm{T}_{3}$ alone. Thus, in experiments in which a putative inhibitor was tested, the 40-min perfusion of the test substance was preceded and followed by 40-min periods during which $\left[{ }^{125} \mathrm{I}\right] \mathrm{T}_{3}$ alone was perfused. Placenta effluent fractions were collected and analyzed for iodothyronine content during the last $20 \mathrm{~min}$ of the three 40 -min perfusion periods. In our perfusion system, 20 min elapsed before steady-state conditions were observed in placenta effluent samples after the onset of perfusion. Similarly, a 20min "wash-out" elapsed before effluent content reached background levels after discontinuation of perfusion. Thus, the sampling times employed ensured that samples were not taken during times in which the perfusion conditions were changing.

Analysis of samples. Placenta effluent samples and perfusates were analyzed for iodothyronine content by HPLC. Aliquots $(2 \mathrm{ml})$ of effluent and perfusate samples were lyophilized and iodothyronines were extracted from the lyophilized material with $2.5 \mathrm{ml}$ of $1 \% \mathrm{NH}_{4} \mathrm{OH}$ in methanol. Samples were then centrifuged at $3,000 \mathrm{rpm}$ and the supernatants were decanted and dried under an air stream. The dried samples were reconstituted in $0.5 \mathrm{ml}$ HPLC mobile phase $(48 \% \mathrm{MeOH}, 52 \% 49 \mathrm{mM}$ $\mathrm{NaH}_{2} \mathrm{PO}_{4}$, and $25 \mathrm{mM} \mathrm{H}_{3} \mathrm{PO}_{4}$ ). In this extraction procedure, the recovery of $T_{3}$ relative to the recovery of $3,3^{\prime}-T_{2}$ was $92 \%$, and the recovery of $3^{\prime}-T_{1}$ relative to the recovery of $3,3^{\prime}-T_{2}$ was $106 \%$. The final calculations did not take into account these small differences in relative recovery. Aliquots of the samples containing between 35,000 and $50,000 \mathrm{cpm}$ were subjected to HPLC using a C18 microbondapak column (Millipore/
Waters Chromatography, Milford, MA). Samples were injected, in the presence of HPLC mobile phase, containing $30 \mu \mathrm{g}$ of nonradioactive $T_{3}$, $3,3^{\prime}-T_{2}$, and $3^{\prime}-T_{1}$ markers. Iodothyronines were separated and eluted at an operating pressure of 2,600 p.s.i. and a flow rate of $1.7 \mathrm{ml} / \mathrm{min}$. The iodothyronine markers were detected at a wavelength of $254 \mathrm{~nm}$ and were used as reference points for ${ }^{125}$ I radioactivity eluting from the column. Table I shows the retention times for [ $\left.{ }^{125} I\right]$ iodide and stable $3^{\prime}-T_{1}$, $3,3^{\prime}-T_{2}, 3^{\prime}, 5^{\prime}-T_{2}, 3,5-T_{2}, T_{3}$, and $T_{4}$. HPLC eluate fractions were collected every $0.6 \mathrm{~min}$ and counted in a gamma counter.

Effect of PTU on $T_{3}$ deiodination in placenta microsomes. We previously showed that in the presence of suboptimal dithiothreitol (DTT) concentrations PTU inhibits the inner-ring deiodination of $T_{4}$ in human placenta microsomes (8). When DTT concentrations were optimal, no inhibition of inner ring deiodination was observed. Since $T_{4}$ rather than $T_{3}$ was employed as the substrate for these studies (8), we considered it important to confirm that PTU, in the presence of low DTT concentrations, also inhibits $T_{3}$ deiodination by placenta microsomes. For these studies, human and guinea pig microsomes were prepared as previously described (8) and incubated with outer-ring-labeld [ $\left.{ }^{125} \mathrm{I}\right] \mathrm{T}_{3}, \mathrm{DTT}$, and PTU or PTU diluent. The specific activity of the [ $\left.{ }^{125} \mathrm{I}\right] \mathrm{T}_{3}$ was $1,120 \mu \mathrm{Ci} /$ $\mu \mathrm{g}$. The volume in the incubation tube was $0.45 \mathrm{ml}$ and the final concentrations of $\left[{ }^{125} \mathrm{I}\right] \mathrm{T}_{3}$ and DTT were $4.13 \mathrm{nM}$ and $0.25 \mathrm{mM}$, respectively. Guinea pig microsomal protein was present in a concentration of 1.8 $\mathrm{mg} / \mathrm{ml}$ and human microsomal protein was present in a concentration of $0.9 \mathrm{mg} / \mathrm{ml}$. Incubations were performed at $37^{\circ} \mathrm{C}$ for $30 \mathrm{~min}$ and terminated by the addition of 2 vol of $95 \%$ ethanol per incubation tube. The incubation products were analyzed and quantitated by paper chromatography in a hexane/tertiary amyl alcohol/2 $\mathrm{N}$ ammonium hydroxide (1:5:6) solvent system as previously described (5).

Statistical analyses. Data were analyzed by a two-way analysis of variance with a repeated measures design using the BMDP statistical software package from Stanford University, Palo Alto, CA. StudentNeuman-Keuls multiple range comparison test was used to determine which test substances significantly changed placenta effluent iodothyronine composition. Significance was established at the $95 \%$ confidence level or better.

\section{Results}

Placental metabolism of $\left[{ }^{125} I\right] T_{3}$. Fig. 1 illustrates the composition of placenta effluent from a typical experiment in which the placenta was perfused with $\left[{ }^{125} \mathrm{I}\right] \mathrm{T}_{3}$ in $3 \%$ BSA-KH buffer for $100 \mathrm{~min}$. Steady-state levels of radioactivity were reached in the placenta effluent by the end of the 10-20-min collection

Table I. Retention Times for Iodide and Various Iodothyronines Employing HPLC*

\begin{tabular}{lrc}
\hline Substance & $n$ & Retention timeł \\
\hline & & $\min$ \\
Thyroxine $\left(\mathrm{T}_{4}\right)$ & 11 & $38 \pm 0.6$ \\
3,3',5'-Triiodothyronine $\left(\mathrm{rT}_{3}\right)$ & 13 & $30 \pm 0.4$ \\
3,5,3'-Triiodothyronine $\left(\mathrm{T}_{3}\right)$ & 23 & $18.5 \pm 0.2$ \\
3,3'-Diiodothyronine $\left(3,3^{\prime}-\mathrm{T}_{2}\right)$ or & & \\
$\quad$ 3',5'-diiodothyronine $\left(3^{\prime}, 5^{\prime}-\mathrm{T}_{2}\right)$ & 11 & $12.4 \pm 0.4$ \\
3,5-Diiodothyronine $\left(3,5-\mathrm{T}_{2}\right)$ & 4 & $7.3 \pm 0.2$ \\
3'-Monoiodothyronine $\left(3^{\prime}-\mathrm{T}_{1}\right)$ & 5 & $6.1 \pm 0.4$ \\
Iodide & 10 & $2.9 \pm 0.1$
\end{tabular}

* A C-18 reverse phase microbondapak column (Millipore/Waters Chromatography, Milford, MA) was employed. HPLC was performed under isocratic conditions at an operating pressure of 2,600 p.s.i. and a flow rate of $1.7 \mathrm{ml} / \mathrm{min}$. The mobile phase was $48 \%$ methanol, $52 \%$ sodium phosphate, $\mathrm{pH}$ 3.1-3.4.

$\ddagger$ Mean \pm SE. 


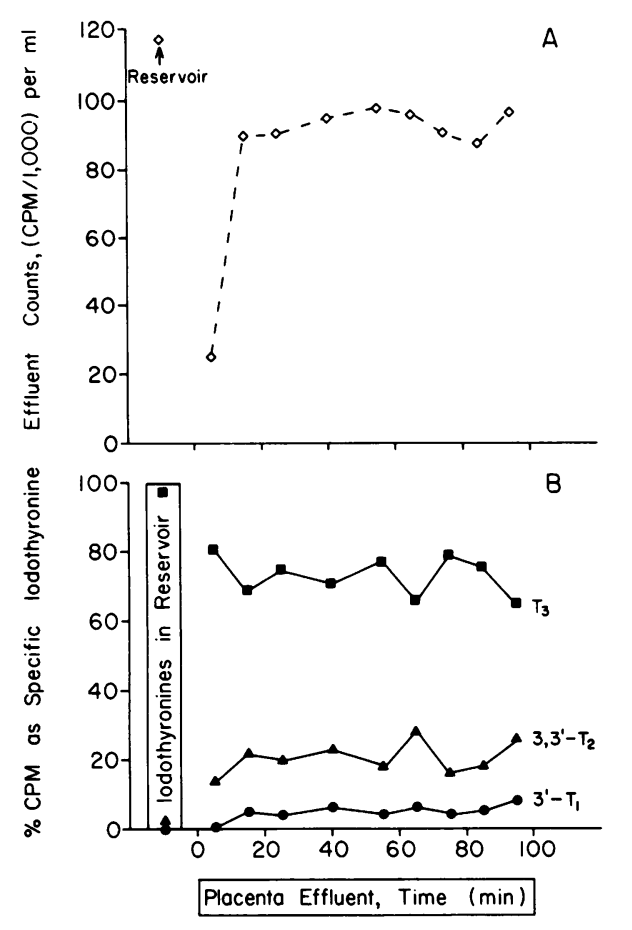

Figure 1. Results of a typical guinea pig placenta perfusion experiment with $120,000 \mathrm{cpm} / \mathrm{ml}\left[{ }^{125} \mathrm{I}\right] \mathrm{T}_{3}$. (A) The concentration of total radioactivity in the perfusion reservoir and in placenta effluent fractions. $(B)$ The percent composition of each iodothyronine in the perfusion reservoir and in the placenta effluent fractions as determined by HPLC.

period. However, in other experiments steady-state radioactivity was not reached until the end of the 20-30-min collection period. In this experiment $98.8 \%$ of the labeled material in the perfusion reservoir buffer could be identified and consisted of $94.4 \%$ $\left[{ }^{125} \mathrm{I}\right] \mathrm{T}_{3}, 2.0 \%\left[{ }^{125} \mathrm{I}\right]$ iodide, and $2.4 \%\left[{ }^{125} \mathrm{I}\right] 3,3^{\prime}-\mathrm{T}_{2}$. In contrast, the placenta effluent samples contained substantially less $\left[{ }^{125} \mathrm{I}\right] \mathrm{T}_{3}$, more $\left[{ }^{125} \mathrm{I}\right] 3,3^{\prime}-\mathrm{T}_{2}$, and measurable amounts of $\left[{ }^{125} \mathrm{I}\right] 3^{\prime}-\mathrm{T}_{1}$. These findings indicate that a fraction of $\mathrm{T}_{3}$ underwent inner-ring deiodination in the perfused placenta to generate $3,3^{\prime}-T_{2}$. A portion of this $3,3^{\prime}-\mathrm{T}_{2}$ was further deiodinated in the inner ring to generate $3^{\prime}-\mathrm{T}_{1}$.

Fig. 2 illustrates the results of five perfusion experiments in which the perfusion conditions were held constant for the entire 120 min of perfusion. Each point represents the mean \pm SE for five separate guinea pig placenta perfusion experiments. In each experiment, three replicate samples were collected during the final $20 \mathrm{~min}$ of each 40 -minute period. This format was also used for the studies shown in Figs. 3-5. It is evident that the percent composition of labeled iodothyronines was constant during the entire $120 \mathrm{~min}$ of perfusion, indicating a steady state of deiodination of $T_{3}$ to $3,3^{\prime}-T_{2}$ and $3,3^{\prime}-T_{2}$ to $3^{\prime}-T_{1}$. The composition of ${ }^{125} \mathrm{I}$-labeled compounds in the perfusion buffer that could be identified by HPLC was $95.3 \pm 1.0 \% \mathrm{~T}_{3}$ and $2.5 \pm 0.7 \%$ $3,3^{\prime}-T_{2}$. As compared to the percent iodothyronines in the perfusion buffer, the mean composition of labeled iodothyronines in the placenta effluent samples for all time periods was $70.2 \pm 2.1 \% \mathrm{~T}_{3}(P<0.01), 20.1 \pm 1.8 \% 3,3^{\prime}-\mathrm{T}_{2}(P<0.01)$, and $8.2 \pm 0.9 \% 3^{\prime}-\mathrm{T}_{1}(P<0.01)$. In these five experiments, $84 \pm 8.8 \%$ of the total amount of radioactivity that perfused the placenta was recovered in the placenta effluent samples. Some radioactivity $(3,000 \mathrm{cpm} / \mathrm{ml}$ or less) could be identified in maternal

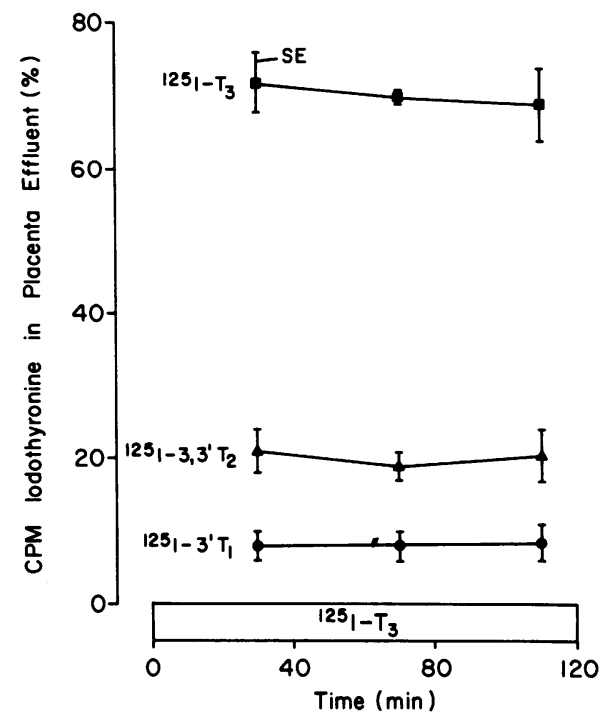

Figure 2. Metabolism of $\left[{ }^{125} \mathrm{I}\right] \mathrm{T}_{3}$ during 120 -min perfusions of guinea pig placenta. The results of five perfusion experiments in which constant conditions were maintained throughout each perfusion are shown.

serum at the end of the perfusions. However, this amount of radioactivity was insufficient for analysis of the labeled substances. Some radioactivity also appears to be withheld within placental tissue or placental microcirculation, given that the radioactivity in placenta effluents logarithmically decreases to background levels during the first $20 \mathrm{~min}$ after discontinuation of perfusion with $\left[{ }^{125} \mathrm{I}\right] \mathrm{T}_{3}$.

Effect of $I A$ on the placental metabolism of $\left[{ }^{125} I\right] T_{3}$. Fig. 3 illustrates the results of perfusion experiments in which $1 \mathrm{mM}$ IA was introduced into the perfusion medium during the 40 80 -min period of the study. It is apparent that the composition of $\left[{ }^{125} \mathrm{I}\right] \mathrm{T}_{3}$ in the placenta effluent was significantly increased $(P<0.01)$ during the time in which IA was perfused as compared with the base line (i.e., the $0-40$-min perfusion period). The percentage of $\left[{ }^{125} \mathrm{I}\right] 3,3^{\prime}-\mathrm{T}_{2}$ and $\left[{ }^{125} \mathrm{I}\right] 3^{\prime}-\mathrm{T}_{1}$ in the effluent also significantly decreased $(P<0.01$ for both labeled metabolites). After IA was removed from the perfusion buffer, the percent composition of $\left[{ }^{125} \mathrm{I}\right] \mathrm{T}_{3}$ in the placenta effluent significantly decreased $(P<0.01)$ and the $\left[{ }^{125} \mathrm{I}\right] 3,3^{\prime}-\mathrm{T}_{2}$ content of placenta effluent samples significantly increased $(P<0.01)$. The iodothyronine composition of the placenta effluent during IA infusion was similar to the perfusion buffer, which suggests that the inhibition of deiodinase activity was nearly complete. It is apparent, therefore, that $1 \mathrm{mM}$ IA acutely inhibited the inner-ring deiodination of $\left[{ }^{125} \mathrm{I}\right] \mathrm{T}_{3}$ in the intact placenta. IA also inhibited the inner deiodination of $3,3^{\prime}-T_{2}$ to $3^{\prime}-T_{1}$. However, recovery from this inhibitory effect during the final $40 \mathrm{~min}$ was not complete, since $\left[{ }^{125} \mathrm{I}\right] 3^{\prime}-\mathrm{T}_{1}$ remained undetectable in the placenta effluent and there was less conversion of $\left[{ }^{125} \mathrm{I}\right] \mathrm{T}_{3}$ to $\left[{ }^{125} \mathrm{I}\right] 3,3^{\prime}-\mathrm{T}_{2}$ as compared to the first $40 \mathrm{~min}$ of perfusion $(P<0.05)$.

Effect of PTU on the placental metabolism of $\left[{ }^{125} I\right] T_{3}$. Fig. 4 demonstrates the results of three perfusion experiments in which $3 \mathrm{mM}$ PTU was introduced into the perfusion buffer during the 40-80-min period. The percent composition of labeled iodothyronines was similar during all periods. Thus, PTU had no significant effect on inner-ring deiodination of $T_{3}$ in the intact placenta perfused in situ. In contrast, the addition of PTU to 


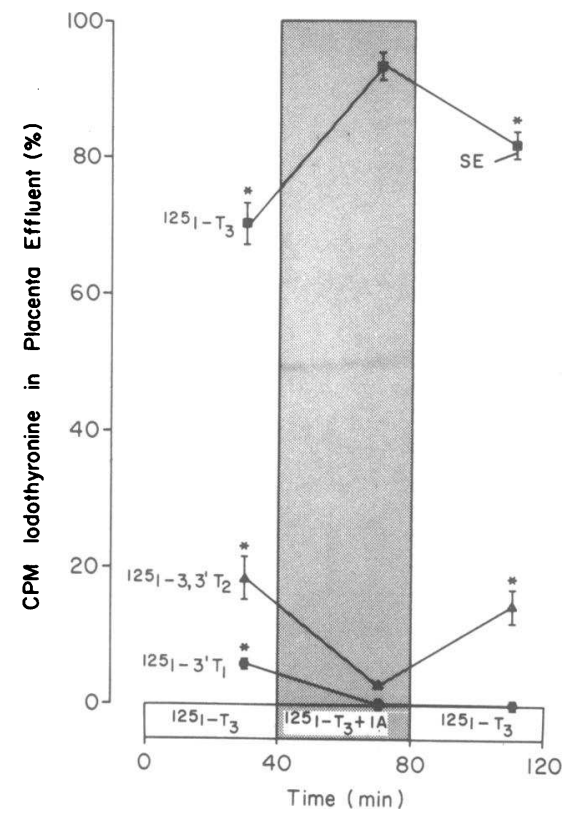

Figure 3. Effect of IA on the metabolism of $\left[{ }^{125} \mathrm{I}\right] \mathrm{T}_{3}$ in the perfused guinea pig placenta. Shown is the percent composition of ${ }^{125} \mathrm{I}$-labeled iodothyronines in placenta effluent fractions during perfusion with $\left[{ }^{125} \mathrm{I}\right] \mathrm{T}_{3}$ alone (0-40 min), during perfusion with [ $\left.{ }^{125} \mathrm{I}\right] \mathrm{T}_{3}$ and $1 \mathrm{mM}$ IA (40-80 min), and after the perfusion was continued with $\left[{ }^{125} \mathrm{I}\right] \mathrm{T}_{3}$ alone (80-120 $\min ) . n=5 ; *, P<0.01$ vs. IA.

human and guinea pig placenta microsomes in the presence of $0.25 \mathrm{mM}$ DTT significantly inhibited the inner-ring deiodination of $\mathrm{T}_{3}(P<0.001)$ (Table II).

Effect of nonradioactive $T_{3}$ on the placental metabolism of $\left[{ }^{125} I\right] T_{3}$. Fig. 5 illustrates studies in which the $T_{3}$ substrate concentration perfusing the placenta was increased from 0.14 to $140 \mathrm{nM}$ during the $40-80-\mathrm{min}$ period of perfusion (in these

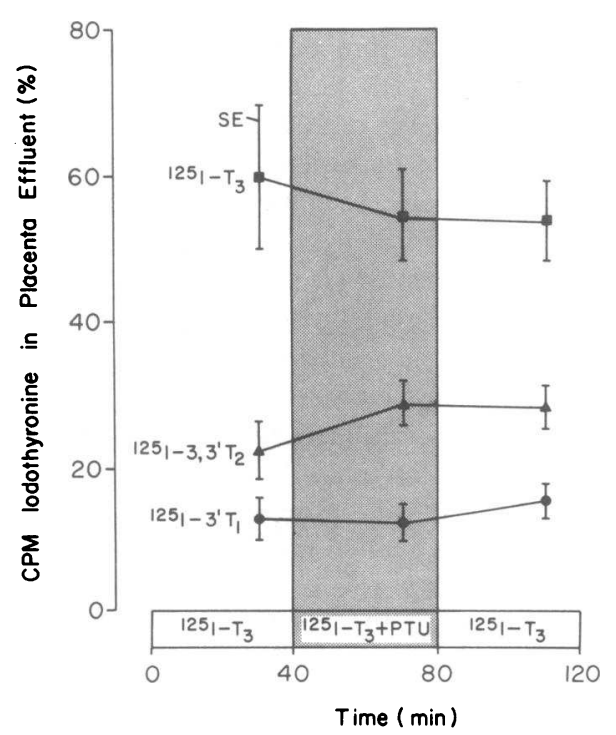

Figure 4. The metabolism of $\left[{ }^{125} \mathrm{I}\right] \mathrm{T}_{3}$ in the perfused guinea pig placenta in the presence and absence of PTU. Shown is the percent composition of ${ }^{125} \mathrm{I}$-labeled iodothyronines in placenta effluent fractions during perfusion with $\left[{ }^{125} \mathrm{I}\right] \mathrm{T}_{3}$ alone $(0-40 \mathrm{~min})$, during perfusion with ${ }^{[25} \mathrm{I}_{\mathrm{T}} \mathrm{T}_{3}$ and $3 \mathrm{mM}$ PTU (40-80 $\left.\mathrm{min}\right)$, and after the perfusion was continued with $\left[{ }^{125} \mathrm{I}_{3} \mathrm{~T}_{3}\right.$ alone $(80-120 \mathrm{~min}) . n=3$.
Table II. Effect of PTU on Inner-ring Deiodination of $\left[{ }^{125} I\right] T_{3}$ in Placenta Microsomes

\begin{tabular}{llll}
\hline Species & PTU $(3 \mathrm{mM})$ & $n$ & $3,3^{\prime}-\mathrm{T}_{2}+3^{\prime}-\mathrm{T}_{1}$ (production) \\
\hline & & & pmol/tube \\
Guinea pig & 0 & 6 & $1.46 \pm 0.03$ \\
Guinea pig & + & 6 & $1.02 \pm 0.04 \ddagger$ \\
Human & 0 & 6 & $1.36 \pm 0.01$ \\
Human & + & 6 & $0.62 \pm 0.01 \ddagger$
\end{tabular}

Final concentration of DTT was $0.25 \mathrm{mM}$.

$*$ Mean \pm SE.

$\ddagger P<0.001$ for the comparison of $3,3^{\prime}-\mathrm{T}_{2}+3^{\prime}-\mathrm{T}_{1}$ production in the presence and absence of PTU.

studies, specific activity of $\left[{ }^{125} \mathrm{I}\right] \mathrm{T}_{3}$ used was $\left.1,133 \mu \mathrm{Ci} / \mu \mathrm{g}\right)$. During perfusion with $140 \mathrm{nM} \mathrm{T}_{3}(40-80 \mathrm{~min})$, the percent $\left[{ }^{125} \mathrm{I}\right] \mathrm{T}_{3}$ in the placenta effluent fractions was significantly increased $(P$ $<0.05)$ and the percent $\left[{ }^{125} \mathrm{I}\right] 3,3^{\prime}-\mathrm{T}_{2}$ was significantly decreased $(P<0.05)$ as compared with values during the $0-40$-min period $\left(0.14 \mathrm{nM} \mathrm{T}_{3}\right)$. While the absolute rate of deiodination of $\mathrm{T}_{3}$ increased from $38 \mathrm{fmol} / \mathrm{min}$ to $21 \mathrm{pmol} / \mathrm{min}$, the fractional rate of deiodination of $\left[{ }^{125} \mathrm{I}\right] \mathrm{T}_{3}$ decreased from $27.3 \%$ to $15.4 \%$. During the last $40 \mathrm{~min}$ of the perfusion (80-120 $\mathrm{min}$ ), when the perfusing concentration of $\left[{ }^{125} \mathrm{I}\right] \mathrm{T}_{3}$ was again $0.14 \mathrm{nM} \mathrm{T}_{3}$, there was some increase in the percent $\left[{ }^{125} \mathrm{I}\right] \mathrm{T}_{3}$ that underwent innerring deiodination.

Outer ring deiodination of $\left[{ }^{125} I\right] T_{3}$. The percent $\left[{ }^{125} \mathrm{I}\right]$ iodide in the perfusion buffer and the placenta effluent samples for all the experiments reported in Figs. 2-5 is summarized in Table

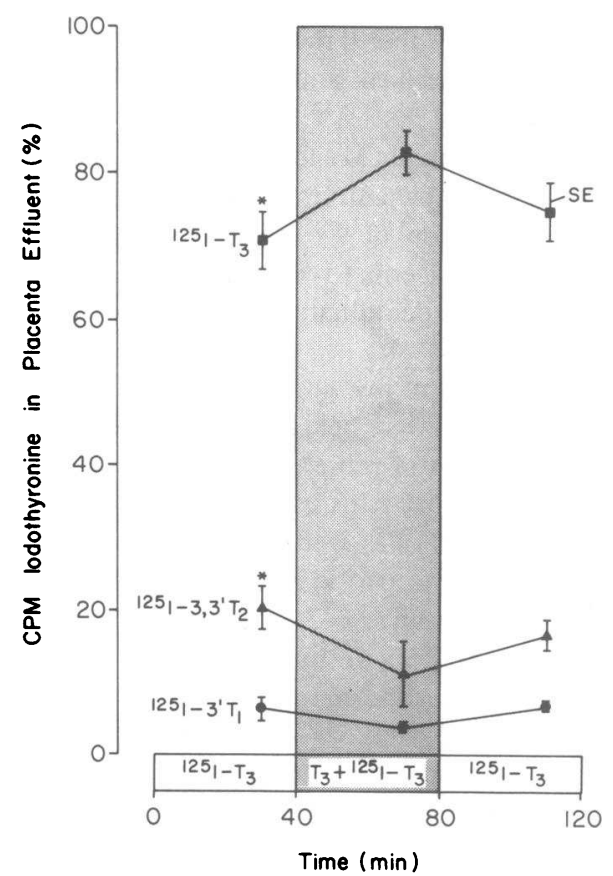

Figure 5. The metabolism of $\left[{ }^{125} \mathrm{I}\right] \mathrm{T}_{3}$ in the perfused guinea pig placenta in the presence of different concentrations of stable $T_{3}(0.14$ and $140 \mathrm{nM}$ ). During the $0-40$ - and 80-120-min periods, high specific activity $(1,120 \mu \mathrm{Ci} / \mu \mathrm{g})\left[{ }^{125} \mathrm{I}\right] \mathrm{T}_{3}$ was perfused in a concentration of 0.14 $\mathrm{mM}$. During the $40-80-\mathrm{min}$ period, low specific activity $(1 \mu \mathrm{Ci})$ $\left[{ }^{125} \mathrm{I}_{\mathrm{T}} \mathrm{T}_{3}\right.$ was perfused in a concentration of $140 \mathrm{nM} . n=4 ; *, P<0.05$ vs. $T_{3}$. 
Table III. $\left[{ }^{[25}\right.$ I]Iodide in Guinea Pig Placenta

\begin{tabular}{|c|c|c|c|c|}
\hline \multirow[b]{2}{*}{$\begin{array}{l}\text { Experimental } \\
\text { groups* }\end{array}$} & \multicolumn{4}{|c|}{$\left[{ }^{[25} \mathrm{I}\right] \mathrm{Iodide}$ as percent of total cpm } \\
\hline & PB & $\begin{array}{l}\text { PE: } 0-40 \\
\min \end{array}$ & $\begin{array}{l}\text { PE: } 40- \\
80 \text { min }\end{array}$ & $\begin{array}{l}P E: 80- \\
120 \mathrm{~min}\end{array}$ \\
\hline I & $0.8 \pm 0.2$ & $0.8 \pm 0.2$ & $1.1 \pm 0.3$ & $1.4 \pm 0.3$ \\
\hline II & $1.4 \pm 0.4$ & $0.9 \pm 0.3$ & $1.3 \pm 0.3$ & $0.6 \pm 0.2$ \\
\hline III & $3.2 \pm 2.2$ & $2.4 \pm 1.5$ & $2.3 \pm 0.7$ & $2.0 \pm 0.4$ \\
\hline IV & $3.0 \pm 1.7$ & $4.7 \pm 2.5$ & $3.3 \pm 1.4$ & $3.2 \pm 1.2$ \\
\hline Mean & $2.0 \pm 0.6$ & $2.3 \pm 0.8$ & $2.0 \pm 0.5$ & $1.8 \pm 0.4$ \\
\hline
\end{tabular}

The percent composition of $\left[{ }^{125} \mathrm{I}\right]$ iodide in perfusion buffer $(\mathrm{PB})$ and placenta effluent (PE) samples in studies in which $\left[{ }^{125} \mathrm{I}\right] \mathrm{T}_{3}$ was perfused through the guinea pig placenta.

* Experimental groups I to IV refer to the studies reported in Figs. 25 , respectively. Group I, constant infusion of $0.14 \mathrm{nM}\left[{ }^{125} \mathrm{I}\right] \mathrm{T}_{3}$. Group II, $\left[{ }^{125} \mathrm{I}\right] \mathrm{T}_{3}+$ iopanoic acid. Group III, $\left[{ }^{125} \mathrm{I}\right] \mathrm{T}_{3}+$ PTU. Group IV, $\left[{ }^{125} \mathrm{I}\right] \mathrm{T}_{3}$ at concentrations of 0.14 and $140 \mathrm{nM}$.

III. The $\left[{ }^{125} \mathrm{I} \mathrm{T}_{3}\right.$ that was employed in these studies was contaminated with small amounts of $\left[{ }^{125} I\right]$ iodide $(2.0 \pm 0.6 \%$, mean $\pm S E)$. The percent $\left[{ }^{125} \mathrm{I}\right]$ iodide was similar in perfusion buffer and placenta effluent samples, indicating no demonstrable generation of $\left[{ }^{125} \mathrm{I}\right]$ iodide from $\left[{ }^{125} \mathrm{I}\right] \mathrm{T}_{3}$ in perfused placenta.

\section{Discussion}

The rat and human placenta contain relatively large amounts of an iodothyronine tyrosyl deiodinase enzyme $(4,5,7)$. The enzyme has been localized to the microsomal fraction of placenta homogenates and has an absolute requirement for sulfhydryl reducing agents regardless of the purity of the preparation (8). Microsomal preparations of placenta tyrosyl ring deiodinase are inhibited by various pharmacological agents, including IA and PTU (8). However, there are no reports on the effects of these agents on iodothyronine tyrosyl deiodinase in the intact placenta in vivo. In fact, information on iodothyronine metabolism in the intact placenta is limited. Cooper et al. (9) have studied the metabolism of labeled $\mathrm{T}_{4}$ and $\mathrm{rT}_{3}$, but not $\mathrm{T}_{3}$, in the perfused guinea pig placenta. They observed no tyrosyl ring deiodination of $\mathrm{rT}_{3}$ when $\mathrm{rT}_{3}$ was perfused into the fetal side of the placenta, but did note tyrosyl ring deiodination of $\mathrm{T}_{4}$ when this iodothyronine was perfused. However, the magnitude of $\mathrm{T}_{4}$ tyrosyl ring deiodination was very small, being $<0.4 \%$ in a single pass through the placenta.

To determine the nature and magnitude of $T_{3}$ deiodination in the intact placenta and the influence of IA and PTU, we employed a guinea pig perfusion system adapted from the method of Kihlstrom and Kihlstrom (10). It was identical in terms of perfusion buffer, flow rate, perfusion pressure, albumin concentration, and temperature, and it used a thermostatically controlled chamber to maintain constant temperature (10). This system has been used in many previous studies of placenta physiology (12); it is ideal for studies of species with hemochorial placentation, as in, for example, man and rodents. Although most published studies on placental deiodination have been performed with rat and human homogenates, the use of these species for perfusion of the intact placenta presents certain limitations. The umbilical vessels of the rat are too small to cannulate and the perfusion models for the human placenta are less physio- logical because, unlike the guinea pig perfusion system, the maternal relationships to the placenta are disrupted.

The $\left.{ }^{125} \mathrm{I}\right] \mathrm{T}_{3}$ used in these studies was labeled in the $3^{\prime}$-position. Therefore, the labeled products of $T_{3}$ inner-ring deiodination are $\left[{ }^{125} \mathrm{I}\right] 3,3^{\prime}-\mathrm{T}_{2}$, and $\left.\left[{ }^{125} \mathrm{I}\right] 3^{\prime}-\mathrm{T}_{1} \cdot{ }^{125} \mathrm{I}\right]$ Iodide is the only possible labeled product of $\mathrm{T}_{3}$ outer-ring deiodination. Placenta effluents in the present studies contained small amounts of $\left[{ }^{125} I\right]$ iodide. However, since the percent $\left[{ }^{125} I\right]$ iodide in the placenta effluent samples was similar to that in the perfusion buffer, no outer-ring deiodination of $\mathrm{T}_{3}$ during placenta perfusion was evident. Cooper et al. (9) also did not observe outer-ring deiodination of $\mathrm{T}_{4}$ or $\mathrm{rT}_{3}$ when these compounds were perfused through the fetal side of the placenta. This is in contrast to the recent report of Kaplan and Shaw (6) that rat and human placenta contains an outer-ring deiodinase when either $\mathrm{T}_{4}$ or $\mathrm{rT}_{3}$ were employed as substrates. In their study, outer-ring deiodinase activity could only be detected at low substrate concentrations, which consisted of $2 \mathrm{nM}$ in the case of $\mathrm{rT}_{3}$ or $0.15 \mathrm{nM}$ in the case of $T_{4}$. They did not report results using $T_{3}$ as substrate. It is possible that the failure of Cooper et al. (9) to observe outerring deiodination of $\mathrm{T}_{4}$ in the intact placenta was due to the fact that they employed higher $T_{4}$ substrate concentrations of 46 nM. However, no outer-ring deiodinase activity was noted when $\mathrm{rT}_{3}$ was perfused in tracer concentrations (specific activity was not specified). Kaplan and Shaw (6) also noted that the activity of outer-ring deiodinase in the placenta was greatest in the zone immediately adjacent to the uterine wall. Therefore, iodothyronines that circulate in the fetal side of the placenta may have limited access to the outer-ring deiodinase enzyme described by Kaplan and Shaw (6).

Although we could not detect outer-ring deiodination of $\mathrm{T}_{3}$ in the perfused placenta, tyrosyl or inner-ring deiodination of $\mathrm{T}_{3}$ was clearly demonstrated under conditions in which $0.14 \mathrm{nM}$ $\mathrm{T}_{3}$ was perfused. Approximately $27 \%$ of the $\mathrm{T}_{3}$ was deiodinated to $3,3^{\prime}-T_{2}$ and $3^{\prime}-T_{1}$ in a single pass through the placenta. When $140 \mathrm{nM} \mathrm{T}_{3}$ was perfused, the fractional conversion of $\mathrm{T}_{3}$ to 3,3'$T_{2}$ and $3^{\prime}-T_{1}$ was $15 \%$. These results for $T_{3}$ are much higher than the fractional conversion rate of $0.4 \%$ observed by Cooper et al. (9) when $T_{4}$ was perfused at a concentration of $46 \mathrm{nM}$, and are compatible with our previous observations that $T_{3}$ is the preferred substrate for the inner-ring deiodinase enzymes in rat and human placentas $(4,5)$. In contrast to Cooper et al.'s study, the $\left[{ }^{125} \mathrm{I}\right]$ $\mathrm{T}_{3}$ concentration employed in our study approximated serum $T_{3}$ concentrations in the term fetal guinea pig. Total serum $T_{3}$ levels at term at $0.4 \pm 0.03 \mathrm{nM}$ and free $T_{3}$ levels are $1.64 \pm 0.13$ $\mathrm{pM}$ (mean $\pm \mathrm{SD}, n=6$ ) (13). Thus, our results indicate that the guinea pig placenta is capable of substantial $T_{3}$ metabolism at physiologic concentrations. The rapid rate of $T_{3}$ deiodination by the placenta may provide a partial explanation for the observation that severance of the umbilical cord is associated with an increase in plasma $T_{3}$ concentration at the time of delivery (14). Since the plasma concentration of a hormone is equal to its production rate divided by its metabolic clearance rate (15), cutting the umbilical cord would likely have an important impact in decreasing the metabolic clearance rate of $T_{3}$ by eliminating a major and rapid site for $T_{3}$ deiodination. This, in turn, would result in an increased plasma $T_{3}$ concentration. In fact, metabolic clearance rates of $T_{3}$ have been shown to be much higher in fetal sheep than in adults $(16,17)$. The ratio of $T_{3}$ production in the fetal circulation as compared with the maternal circulation is not precisely known due to lack of sensitivity of the methods $(16,17)$. 
$T_{3}$, because of its rapid deiodination, is an ideal substrate for the study of acute drug effects under conditions similar to those obtained in vivo. The present study shows that IA has a rapid and reversible inhibitory effect on iodothyronine innerring deiodinase in the intact placenta. We have previously reported that PTU inhibits the tyrosyl-ring deiodination of $T_{4}$ by human and rat placenta homogenates and microsomes when incubations are carried out in the presence of low DTT concentrations, but not when DTT is present in concentrations that are optimal for enzyme activity. As shown in the present study, PTU also inhibits $T_{3}$ tyrosyl-ring deiodination in human and guinea pig microsomes incubated in the presence of low DTT concentrations. The observation that PTU does not inhibit $T_{3}$ tyrosyl ring deiodinase activity in the in situ perfused placenta suggests that, under in vivo conditions, the placenta may have a relatively abundant supply of endogenous cofactors required for $\mathrm{T}_{3}$ deiodination. It is also possible that intracellular concentrations of PTU in vivo were too low to produce enzyme inhibition. However, since PTU crosses the placenta (18), it seems likely that some PTU does enter the thin layer of trophoblastic cells that separates the fetal and maternal circulations.

Obviously, the perfused guinea pig placenta is of limited use for detailed kinetic studies of deiodination, studies that involve comparison of multiple perturbations, or those that require prolonged longitudinal observations. These limitations are due to the fact that, ideally, all observations must be made within a relatively short period of time. However, the present studies show that information can be obtained that is in many ways more physiologically and clinically relevant than that obtained in disrupted cell and organ preparations or in cultured cells. PTU is administered to pregnant women with hyperthyroidism and is known to traverse the placenta and to reach the fetal circulation (18). IA is generally not administered to pregnant women, but recent studies have suggested that this class of compounds may be useful in treating Graves' Disease (19). It is possible that the administration of IA - but not PTU-to pregnant women could affect placental tyrosyl deiodination of $T_{3}$, although the extent of this effect and its clinical relevance remains unclear. Further studies on the effects of maternally administered IA and PTU on placenta inner-ring deiodinase activity may yield information on this point.

In summary, the present study demonstrates that $T_{3}$ is very actively deiodinated in the tyrosyl ring by the intact guinea pig placenta. It suggests that the placenta is a major site of $T_{3}$ disposal in the fetus. Therefore, the activity of the placenta deiodinase may influence fetal serum $T_{3}$ concentrations. Despite the fact that PTU inhibits inner-ring deiodinase in placenta homogenates, the present studies suggest that PTU may not affect inner-ring deiodinase in the intact placenta. Therefore, it is possible that its use in pregnant women may not be associated with impaired placental deiodination of fetal $\mathrm{T}_{3}$. Iopanoate and related compounds, however, are likely to impair placental tyrosyl ring deiodination of the iodothyronines and affect fetal thyroid hormone metabolism.

\section{Acknowledgments}

We thank Dr. Anthony Jennings for helpful discussions on the HPLC of iodothyronines and Dr. Christopher Longcope for helpful discussions on concepts of in vivo metabolism. Mrs. Linda Desai provided excellent secretarial assistance.

This study was supported by National Institutes of Health grants AM 27850, AM 18919, and AM 07270.

\section{References}

1. Nuwayhid, B. S. 1981. Fetal homeostasis. In Principles and Practice of Obstetrics and Perinatology. L. Iffy and H. Kaminetzky, editors. John Wiley and Sons, Inc., New York. 272.

2. Louros, N., C. Miras, and A. Urettos. 1964. La desiodation in vitro de la thyroxine par le placenta humain. Ann. Endocrinol. 25:417422.

3. Banovac, K., L. Bzek, T. Tislaric, and M. Selso. 1980. Conversion of thyroxine to triiodothyronine and reverse triiodothyronine in human placenta and fetal membranes. Horm. Res. (Basel). 12:253-259.

4. Roti, E., S. L. Fang, K. Green, C. H. Emerson, and L. E. Braverman. 1981. Human placenta is an active site of thyroxine and 3,3'5-triiodothyronine tyrosyl ring deiodination. J. Clin. Endocrinol. Metab. 53: 498-501.

5. Roti, E., S. L. Fang, L. E. Braverman, and C. H. Emerson. 1982. Rat placenta is an active site of inner ring deiodination of thyroxine and 3,3',5-triiodothyronine. Endocrinology. 110:34-37.

6. Kaplan, M. M., and E. Shaw. 1984. Type II iodothyronine 5'deiodination by human and rat placenta in vitro. J. Clin. Endocrinol. Metab. 59:253-257.

7. McCann, V. D., E. A. Shaw, and M. M. Kaplan. 1984. Iodothyronine deiodination reaction types in several rat tissues: effects of age, thyroid status, and glucocorticoid treatment. Endocrinology. 114:15131521.

8. Fay, M., E. Roti, S. L. Fang, G. Wright, L. E. Braverman, and C. H. Emerson. 1984. The effects of propylthiouracil, iodothyronines, and other agents on thyroid hormone metabolism in human placenta. J. Clin. Endocrinol. Metab. 58:280-286.

9. Cooper, E., M. Gibbons, C. R. Thomas, C. Lowy, and C. W. Burke. 1983. Conversion of thyroxine to 3,3'-5'-triiodothyronine in the guinea pig placenta: in vivo studies. Endocrinology. 112:1808-1815.

10. Kihlstrom, I., and J. E. Kihlstrom. 1981. An improved technique for perfusion of the guinea pig placenta in situ giving viable conditions demonstrated by placental transport of amino acids (L- and D-alanine). Biol. Neonate. 39:150-159.

11. Rajatanavin, R., R. A. Young, and L. E. Braverman. 1984. Effect of chloride on serum thyroxine binding in familial dysalbuminemic hyperthyroxinemia. J. Clin. Endocrinol. Metab. 58:388-391.

12. Roudolph, H. L., M. A. Heyman, M. A., K. Teramo, N. Raiha, and C. T. Barrett. 1971. Studies on the circulation of the previable fetus. Pediatr. Res. 5:452-465.

13. Castro, M., S. Alex, R. A. Young, L. Braverman, and C. Emerson. 1986. Total and free serum thyroid hormone concentrations in fetal and adult pregnant and nonpregnant guinea pigs. Endocrinology. 118: In press.

14. Sack, J. M., M. Beaudry, P. V. DeLamater, W. Oh, and D. A. Fisher. 1976. Umbilical cord cutting triggers hypertriiodothyronemia and non-shivering thermogenesis in the newborn lamb. Pediatr. Res. 10:169-175.

15. Baird, D. T., R. Horton, C. Longcope, and J. F. Tait. 1969. Steroid dynamics under steady state conditions. Rec. Prog. Horm. Res. 25:611-664.

16. Fisher, D. A., J. H. Dussault, A. Erenberg, and R. W. Lam. 1972. Thyroxine and triiodothyronine metabolism in maternal and fetal sheep. Pediatr. Res. 6:894-899.

17. Chopra, I. J., J. Sack, and D. A. Fisher. 1975. 3,3',5'-Triiodothyronine (reverse $T_{3}$ ) and 3,3',5-triiodothyronine $\left(T_{3}\right)$ in fetal and adult sheep: studies of metabolic clearance rates, production rates, serum binding, and thyroidal content relative to thyroxine. Endocrinology. 97: 1080-1088.

18. Merchant, B., B. E. W. Brownlie, D. McKay-Hart, P. W. Horton, and W. D. Alexander. 1977. The placental transfer of propylthiouracil, methimazole, and carbimazole. J. Clin. Endocrinol. Metab. 45:11871193.

19. Wu, S. Y., T. P. Shyh, I. J. Chopra, D. H. Solomon, H. W. Huang, and P. C. Chu. 1982. Comparison of sodium ipodate (oragraffin) and propylthiouracil in early treatment of hyperthyroidism. J. Clin. Endocrinol. Metab. 54:630-634. 